\title{
Should Philosophy of Sport Matter
}

\section{More?}

\author{
R. Scott Kretchmar
}

Penn State University, USA

\section{KEYWORDS}

\begin{abstract}
While the philosophy of sport has registered significant gains in stature over the past 40 years, and while its future looks bright quite apart from any enhanced interventions by ourselves, I suggest that the philosophy of sport should still matter more. The achievement of this end, I argue, can be expedited by heeding Spinoza's philosophy of unity, Merleau-Ponty's emphasis on embodiment, and Dewey's focus on the aesthetics of experience. While other philosophers and their works might be used for the same purpose, I claim that it would be difficult to find three more accommodating allies. The major portion of the essay is devoted to defending this assertion.

philosophy, sport, significance, unity, embodiment, aesthetics of experience
\end{abstract}

Should philosophy of sport matter more? This question, in its current form, is difficult to answer because we need to ask two further questions to make any sense of it: "matter more than what" and "matter more to whom." My answer to the former question would be this: "matter more than it currently does on average." And I am thinking it should matter more, not so much to current sport philosophers (For some of these folks who spend sleepless nights wrestling with sport philosophy questions, one could argue that it should matter less.) but I am thinking of some of our academic colleagues in the University. For many of them, philosophy of sport, I will argue, should matter more.

It is not that sport philosophers have not made considerable progress over the past 40 years or so. We have several sport philosophy societies around the world, a number of good journals that accept our work, and a growing number of scholars who have been attracted to our subject matter. The recent sport philosophy conference in Rome that boasts the highest number of papers ever for an International Association for the Philosophy of Sport meeting is a case in point. The fact that many attendees are young scholars that have their best work ahead of them provides even more reason for optimism.

But the fact remains that our sub-discipline resides in the shadows cast by two academic clouds. One cloud is produced by philosophy, the other by sport. Those of us who live in kinesiology departments, units that are populated by exercise physiologists, motor control scholars, sport psychologists and other scientists who often attract large grants, are marginalized because well, we do not typically get large grants and we do not measure anything. As one of my scientific colleagues at Penn State described it, "We do real research," with the clear implication that we philosophers do not. Those of you who reside in philosophy or humanities departments are often marginalized by other university departments that are given better resources and more attention and whose faculty members are typically better paid. Moreover, pragmatic and materially-oriented students seem to be flocking to 
majors other than philosophy, history, and literature - that is, to majors that are associated with wellpaying jobs. Recent data suggest that students majoring in the humanities in the United States has declined from around $30 \%$ to less than $16 \%$ in just one generation (Chace 2009). So, there is a foundational sense in which we matter less, just as all humanities professors matter less, quite independent of the quirky sport-related subject matter that we study.

But it is our unique subject matter, of course, that casts the second shadow. According to some accounts, sport is only a pastime, a sideshow to the main business of life, childish play, unproductive, even counterproductive in its highly commercialized, hypercompetitive forms. Other than the fact that some forms of sport may be socially, politically, and economically significant, sporting activity undressed, and by itself, seems relatively trivial. Sport, as it is often said in a pejorative tone, " is only a game."

Many of us, of course, do not believe that. Or more accurately said, even though we may agree that sport is a game, we do not count that as any reason for ignoring it or denigrating its status. Regardless, games do not command the respect engendered by other topics. Others in the academy have similar problems. For instance, we share something of a common fate with those who study television soap operas, the cultural intrigue of riding roller coasters, and the purported play activities of cockroaches. But arguably we are among a small minority of scholars who are systematically marginalized because, as "philosophers of the inconsequential," we reside under two clouds that cast shadows across the academic terrain.

I will argue in this paper that, no matter how we respond to this state of affairs, things will get better. The clouds, to a degree, will part. I am confident, for instance, that integrated, crossdisciplinary research will require the perspectives of philosophy and that more holistic views of human nature will elevate the significance of such activities as play, dance, games, and sport. The only question in my mind is how fast this will happen. The purpose of this paper is to investigate several ways in which we might expedite the process.

With the help of Spinoza, Merleau-Ponty, and Dewey, I will look at three ways in which we might assist others in seeing that philosophy of sport should matter more. I am not suggesting that we should be overly self conscious, defensive, or least of all, that we should spend the majority of our thought and energy on improving our political position in our universities. I see this progress mostly as a byproduct of how we act, what we study, and the quality of what we produce. Still political realities are important, so we should not bury our heads in the sand as we fight for our place in the academy.

\section{Recommendation 1: Unity and integration}

Spinoza is regarded by many as the great philosopher of unity. Some of you know that his penchant for seeing dissimilars (even polar opposites) as integrated got him into trouble with both the synagogue and the church. This was the case because he regarded what many then thought of as the most other of all others (namely, God) as immanent, as integrated with nature. This led to claims like the one found in the Fifth Part of his Ethics, Proposition XXIV: "The more we understand individual objects, the more we understand God" (Wild, p. 385). And here is a claim about the compatibility of embodiment and eternity: Ethics, Fifth Park, Proposition XXII. "In God, nevertheless, there necessarily exists an idea which expresses the essence of this or that human body under the form of eternity" (Wild, p. 384). These claims, of course, were heresy theologically and the attempt to reconcile two things that seemingly could not be reconciled (God and Nature; eternity and embodied particularity) was utter nonsense in rational secular terms - or at least, so it was to some.

Spinoza, in fact, went on to undermine many of the common dichotomies that were used to explain the world in general or human existence in particular. Inner-outer, subjective-objective, mindbody, thought-emotion, idea-action, free-determined, transcendent-immanent, and other like oppositions fell to his synthesizing analyses. This unity was not won as a result of a reductive 
materialism, but rather a kind of ambiguous monism. Everything, he claimed, (the thoughtful and material) was part of a single system.

Ironically, Spinoza lived at the same time and in the same town for a time (Amsterdam) as Rene' Descartes. One of these individuals (Spinoza) would champion integration and anticipate the later work of other biologically-grounded synthesizers who saw reality as continuous - for instance, American pragmatists (James, Dewey), or existential phenomenologists (Maurice Merleau-Ponty, Gabriel Marcel.) The other (Descartes) would reinforce a dualistic view of personhood that continues to resurface today and, in my judgment, cost us political capital. But I am getting ahead of my story.

Why should we follow Spinoza rather than Descartes? Why are the themes of unity and integration important as we seek to show why the philosophy of sport should matter more? I will provide one political reason and another one that is more substantive. The political reason has to do with our unhappy fate at the hands of what might be called stock dichotomies. Dualistic characterizations of our subject matter hurt us in the academy more often than not. Mind-body, intellectual-nonintellectual, and academic-nonacademic bifurcations undermine our status in our research and teaching institutions. We fare no better when sport is analyzed in terms of activities that are serious or trivial, adult or childish, work or play, real or gratuitous, necessary or unnecessary. The point is not that the sporting side of these dualisms cannot be defended or even, in the hands of a skillful philosopher, turned into an improbable victory. And the point is not that dichotomies have no utility in helping us sort through and draw important distinctions. Rather it is this. In common parlance and thinking, we typically end upon the losing side of these clean and tidy bifurcations whether for good reasons or not. This is the case on the street and in the market place among those who are untutored in metaphysics, and this is also the case in the halls of academe where, in my judgment, people should know better but where old biases die hard and slowly, and where it is often more convenient to deal with reality in terms of either-or options than messy distinctions.

What alternatives do we have for dualism? This is where Spinoza, with his emphasis on unity, integration, and continuity comes into play. We can choose to avoid dualistic characterizations as much as possible and where appropriate. We can avoid the tendency to provide quick, binary answers to those who are curious about the distinctiveness of sport, games, and play. We can emphasize the continuities we see between sport and other related phenomena. We can stay clear of the old normative evaluations associated with the superiority of, for instance, the mind over body, or theory over practice.

This is not a request to distort our subject matter or deceive our critics. Rather it is an appeal for epistemological flexibility, an acknowledgement that there is more than one accurate way to portray our phenomena of interest. Dualistic-tending descriptions can capture part of the truth, but so can more holistic portrayals. Consider how we might describe two positions on an American football field namely, the right and left ends. We could provide a dualistic-tending description as follows: "The right end plays opposite the left end." Or we could provide a portrayal that emphasizes integration: "The right and left ends are separated from the center and quarterback by varying distances and in different directions." The former description plays on our penchant for dyads and exclusivity. "There are two sides on a football field. If you play on the right side, you cannot also, at the same time, play on the left side." The latter description, by way of contrast, makes reference to at least a pair of differences by degree - the greater or lesser distance from the center and quarterback, and the gradations on a directional compass that deviate from 180 degrees or pure opposition. Both descriptions are accurate, albeit in different ways.

If Spinoza's options are viable and if this simple example works for our own metaphysical descriptions, why would we continue to give ourselves unnecessary political problems by tacitly or explicitly reinforcing a dualistic or dualistic-tending metaphysic of our own subject matter? To be sure, there are times and places where sharp dichotomies are needed. But to argue, for instance, that sport is truly academic (rather than nonacademic) or intellectual (rather than nonintellectual) is to 
reinforce those very dualisms that give us trouble in the first place. It is to play the philosophic game, as it were, on their home field, not our own. To fall back on inherited dualisms and dichotomies when other options are available amounts to little more than inflicting harm on ourselves gratuitously.

But whatever the political consequences of relying on dualisms may be, it could also be philosophically unwise to do so. This leads to the more substantive reason for following Spinoza. As noted previously, I believe we face options in how we characterize our subject matter. If we portray it as integrated and ambiguous, we will in my judgment produce a more truthful balance between the continuities and discontinuities, the commonalities and the more or less distinctive features of whatever phenomenon we are analyzing including sport and games.

Here is an example. Much of our literature, for understandable reasons, has emphasized the distinctiveness or uniqueness of our objects of interest. I say this is understandable because topics like play, games, and sport have often received too little academic attention in the past. Thus, it has been natural for us to emphasize their special metaphysical and normative characteristics over their similarities with the rest of reality. When Suits (1978/2005), for example, analyzed games he argued that the lusory attitude both distinguishes game participation from other activities and unifies his definition. To act in lusory ways, to search for gratuitous problems, to seek trouble solely for the sake of the trouble solving experiences such searching and seeking permits makes gaming different, discontinuous, the opposite kind of thinking that motivated the industrious ants in The Grasshopper. Grasshoppers are not really interested in solving their problems. Ants are. Discontinuity, uniqueness, binary opposition and dichotomy characterize much of Suits' analysis.

Often lost in reading Suits, however, is the remarkable similarity he saw between games and work. In fact Suits began his analysis with a characterization of the logic of work (utilitarian efficiency) and then showed that game logic is identical to it. That is, once artificial game hurdles are in place, game participants act just like those in work environments. That is, they try to solve problems as quickly and efficiently as they can. Suits even speculated that we game up life by dragging our feet at work or by engaging in work-like projects (building houses) even when they are not needed. Work, in fact, can include "just right" problems. The only difference is that, in work, they are typically serendipitous. In games, they are intentionally constructed. But in ideal work and in good games, just right problems can be interesting in their own right and, in effect, carry us along on the wings of delight.

So what lies at the heart of gaming? Is it gratuitous logic in dichotomous opposition to the necessities of natural work-based problem solving? Or is it utilitarian efficiency - precisely the same kind of logic that drives our work activities? It is hard to say. Games are ambiguous kinds of animals. In an important sense, they are continuous with other parts of life while, at the same time they show distinctive features. So when we analyze games, why not better balance the distinctive features of this activity with its striking and undeniable continuities with the rest of life - both metaphysically and normatively. This, at once, provides a more accurate and compelling story and serves as a reminder to those who see games as disconnected from supposedly more important core elements of human existence that they need to take a second look.

\section{Recommendation 2: Embodiment}

Merleau-Ponty is regarded by many as the great philosophy of embodiment or embodied intelligence. He broke away from the more aggressive mathematical and geometrical aspirations of philosophers who were impressed by the methods and putative precision of science. At the same time, he paradoxically produced a philosophy that was perhaps more scientifically compatible than any of those who tried to mimic the objectivity of dispassionate observation and measurement. He did something that would have pleased Spinoza. He found a way to bring consciousness down to earth, to situate it, to integrate it with human action, to counter Husserl's transcendental ego with an empirical 
ego the one that is now, as we all know, the subject of cognitive psychology and neuro-anatomy -as well as most of philosophy.

Merleau-Ponty's famous analysis in The Structure of Behavior of the interactive levels of influence in human action is something that anticipated later empirical findings related to, for instance, the complexities of genetic function and expression. Ideals, clear and distinct ideas, emotions, social influences, history and memory, homeostatic mechanisms working at the physiological level, alleles, chemicals - they are all in the mix, somehow internally affecting (and being affected by) one another. With a thunderclap of integration, Merleau-Ponty replaced the Cartesian "I think" with the more biopsychologically inclusive "I can."

Drew Leder (1990) and Maxine Sheets-Johnson (1999) would later amend Merleau-Ponty's thesis and, in a sense, render his turning of the epistemological world upside down even more complete. Leder drew attention to the fact that Merleau-Ponty's integration was still tacitly dualistic because it emphasized human cleverness and creativity and involved mostly our perceptual and motor extremities - our vision, handedness, and footedness. He argued that we also live from our internal organs, our weight, our fundamental and meaty situatedness not just our clever extremities. SheetsJohnson argued that consciousness is more a function of movement than location, of interaction with the world in primordial reaching, grasping, sucking, pushing, pulling, and moving from one place to another. Such basic movement, she suggested, accounts not only for the fact that we have a world, but also how we have it - even down to the details of how we categorize, how we mean, how we intend.

Like Spinoza, Merleau-Ponty and his followers were the subject of considerable criticism. Some thought that they condemned philosophy to the domains of idiosyncratic subjectivity and a vicious form of relativism. If all knowing is inherently and radically perspectival, what do we share? Indeed, what can we share? Dewey, Polanyi, and others had answers to these questions, but these concerns still haunt those philosophers who do not want the body, as it were, to be interposed between thought and reality.

I would argue that we have no greater ally in sport philosophy than Merleau-Ponty. I say this because embodiment, movement, and motor-active "I cans" lie, he argued, at the center of what it means to be human. By implication, this places activities like sport, dance, and exercise very much at the heart of humanity, not the periphery. The noble and cerebral "I believe" and "I hope" cannot be separated from the more visceral "I move."

I find it fascinating that the cognitive sciences are now ratifying what Merleau-Ponty wrote over eighty years ago and what Spinoza forecasted over 300 years before that. Brains and thoughts do not lie in two different worlds. In fact, what our ancestors thought and did shaped the neural structures that you and I carry around in our heads. The motor-related actions that they repeated across the millennia affect how we think today, including of course, what we are even capable of thinking.

In some of my previous work, I've quoted Colin McGinn (1999) in this regard. He points out that our very difficulty in getting our intellectual arms around such conundrums as the mind-body problem is undoubtedly related to the kind of intellection that was required for success among our hunter-gatherer ancestors. Just as we carry some of their assets and liabilities in our cardio-vascular systems, we carry some of their assets and liabilities in our neural architecture and in our daily thought patterns.

Another ally is Howard Gardner who was among the first to argue for multiple, task-specific forms of intelligence. His original work entitled Frames of Mind: The Theory of Multiple Intelligences is still controversial, to be sure, but to my knowledge its central arguments have not been refuted. The idea is simple. Because structure is causally affected by function, and because our ancestors were required to carry out a number of required, domain-specific functions over the millennia, it follows (given the reality of relatively slow evolutionary change) that our own intellectual hardware is not homogenous but at least somewhat specialized. Three of Gardner's seven intelligences (kinesthetic, spatial, and musical) are related to skilled movement directly. The other four (including linguistic and 
logical-mathematical intelligence) are related in fundamental ways - even if less obviously. All this goes to say once again that how we think, and how we are uniquely smart, is integrally related to how our ancestors moved and how we continue to move.

The upshot is that modern science and philosophy are heading, I believe, toward a common conclusion - namely, that we will not figure out human nature unless and until we understand embodiment, movement, the "I cans" from the past that shaped us, and our own evolving "I cans" that will shape those who follow. The renewed emphasis on physicality, basic skilled movement, and the like, turns cross-disciplinary research in our direction. It places the action much closer to us.

Many of us, in fact, gravitated to the philosophy of sport because our intuitions suggested that embodied activities are significant, intelligent, fully human. I think those intuitions are on target, and we should continue to honor them. Other philosophers and empirical scientists appear to be moving in that direction. [See e.g., Damasio (2003) Looking for Spinoza; and Kelso \& Engstrom (2006), The Complementary Nature]. We should take advantage of this and keep embodiment and motor skill at the forefront of our research. If we do this, it is likely that the philosophy of sport will begin to matter more across the University.

\section{Recommendation 3: Experience}

I've saved my favorite theme for last. John Dewey is one of the philosophic champions of experience. As you know, experience comes with a checkered reputation. It is seemingly unavoidable on the one hand, but it is also the source of error on the other. Husserl reflected this ambivalence when he argued that we have to begin our phenomenological reductions from lived experience (what he called the natural standpoint) but then go through a series of reductions to, in effect, nullify potentially corrupting elements related to that experience. He wanted philosophers to be able to intuit the eidetic sense or pure "thinkability" of different phenomena. Periodic returns to common experience were a necessity (He called himself a perpetual beginner.), but the reductions would again be employed in an effort to eliminate sources of unwarranted assumption and error.

Dewey saw things differently. We are required, he thought, to immerse ourselves in experience, reside in experience, reflect, as it were, in and from the somewhat murky waters of experience. Ongoing experience was at once the source of our ideas and the litmus test for their accuracy. In his famous work entitled Art as experience, Dewey wrote about what it is to have an artistic experience:

The idea that the artist does not think as intently and penetratingly as a scientific inquirer is absurd. A painter must consciously undergo the effect of his every brush stroke or he will not be aware of what he is doing and where his work is going. Moreover, he has to see each particular connection of doing and undergoing in relation to the whole that he desires to produce. To apprehend such relations is to think, and is one of the most exacting modes of thought. The difference between the pictures of different painters is due quite as much to differences of capacity to carry on this thought as it is to difference of sensitivity to bare color and to differences in dexterity of execution.

(Dewey 1934/2005, p. 47)

Two things are important here. First, Dewey has thematized experience itself. Experience itself is a topic worthy of philosophic analysis. Second, Dewey is obviously making claims that are grounded in his own personal experience with artistic projects. He avoids phrases like logically required, different in principle, or intuitively obvious, or once again as Husserl might have said, eidetically necessary. Yet, Dewey's analysis operates at a robust level of generality. It is not difficult for us to substitute dancer or athlete everywhere he talks about the painter and the fine-tuned coherence that is monitored in the act of painting.

Sport is an aesthetically rich domain. Because of this, sport stands in contrast to many other common philosophic topics that are less likely to evoke experiential analyses. In fact, when one looks 
across the landscape of central philosophic themes - mind, justice, the good life, freedom, ethics, citizenship, politics, friendship - sport jumps out as a topic of particular aesthetic promise. We love sport, it could be said and indeed has been said, because it engages our emotions. We love it because it arouses our senses and, when done well (and even sometimes when it is not done so well), it simply feels good.

One aesthetic experience that lies at the center of sport is uncertainty. Whether it is the uncertainly of the test (Can I do this difficult thing or not?) or the uncertainty of the contest (Can I do this difficult thing better than you or not?) athletes experience intriguing and delicious challenges in their respective sporting worlds. As some of you in this room have pointed out, this is the stuff of drama. This is what evokes the aesthetics of just right uncertainties or what my beloved mentor Warren Fraleigh (1984) called "sweet tension."

We also have the aesthetics of culture that are so crucial when trying to explain the attraction of sport. Because games are invented by us and for us, they enjoy a degree of flexibility that is not seen in some work settings - settings that more strongly dictate the rules of behavior. So when gamewrights wittingly or unwittingly develop game tests, they are at once adhering to the rules of test making and the rules of political, cultural, and historical promise and consistency. Sporting experiences mean in many ways - as bio-cultural signs, symbols, metaphors, myths, and even spiritual encounters - in fact so much that we cannot say fully how and why they mean. To paraphrase Polanyi, sport means more than we can say. The lived experience of sport is so incredibly rich! Why would we not feature it in our philosophic work?

Students in my classes at Penn State are required to turn in course evaluations at the end of every semester. One of the standard response topics is "interest shown by professor in subject matter." While I do not score well on all the parameters tested, I am usually rated very highly on this one. Why do I exude such enthusiasm? Is it because I enjoy philosophy? Or is it more that I enjoy sport? It is probably a little of both, but I'm quite confident that the sport part plays a big role in students' perceptions.

In that sense, I think we are like our colleagues who teaches the philosophy of art or the philosophy of film. The subject matter itself is evocative. The first-person experience of the things being analyzed is inherently interesting. I realize that some philosophers might argue that I'm being more than a little provincial in ranking the intrigue of my subject matter over theirs, and indeed, I've been in classes in which professors have gotten very worked up over problems in "esse est percipi" and exceedingly emotional as they show the fallacies in Descartes' proof for God's existence. But I still feel that we have a leg up in generating interest in our students when we talk about something they typically love as participants or spectators.

Sport is something that matters to people. We should capitalize on that. But how we capitalize is important. I know that some of us (I have done it myself) will use sport as a vehicle to teach broader lessons on topics that are more central to philosophy proper. (I once taught a class entitled, "The Ethics of Fair Play in Sport and Life.”) There is nothing inherently wrong with this. Sport is a marvelous vehicle for clarifying issues related to fair play, distributive justice, altruism, prisoner's dilemma puzzles, and so on. But the use of sport for other purposes does little to elevate sport as a legitimate topic of interest in its own right or highlight the experience of sport as among the most important challenges and delights of human existence. In a sense, it plays into the hands of those who do not believe that the philosophy of sport matters very much at all.

As someone who is still running, biking, and playing table tennis, I do not see sport primarily as a vehicle for teaching other things. I want my students to appreciate this activity, unadorned, for itself, not primarily as a means to other educational objectives. Experiences of sport do not just provide grist for the philosophic mill when analyzing other topics, nor are physical encounters valuable simply as means to health and physical fitness. When we vigorously share these truths, I think it will be more difficult for our detractors to underestimate the importance of the philosophy of sport. 


\section{Conclusions}

I have argued in this short paper that for both political and substantive reasons we need to follow Spinoza, take his philosophy of unity seriously, downplay dichotomous characterizations of our subject matter and remember that we need to balance our analyses of disjunction with those of integration. Sport shown to be fully integrated with life writ large will be difficult to ignore.

I've also argued that we need to follow Merleau-Ponty and reinforce his emphasis on embodiment and the empirical ego. Skilled movement as a foundational element of the human "I can" elevates motor-intensive exploration, discovery, creativity, and expression. It also suggests that our very ability to think in impressive human ways is tethered to our history as task-specific moving creatures. If Merleau-Ponty and his successors are right, cross-disciplinary work that would uncover anything of significance about human nature, will be required to have philosophers of movement, dance, games, and play at the table.

And I have said that we need to follow Dewey for aesthetic reasons if none other. The experiences of sport, dance, and play are rich. They are worthy of study in their own right. Such experiences give sport philosophers material on which to work. Such experiences motivate us. And such experiences prevent us from justifying sport philosophy simply as a tool for analyzing other supposedly more important philosophic issues.

With or without our help, however, the future is bright. I believe that the philosophy of sport will matter more in the academy. But we can help to speed the process along. I extend best wishes to all my colleagues who are engaged in this worthy enterprise.

\section{REFERENCES}

Chace, W. M. (Autumn, 2009). The decline of the English department. Accessed on September 21, 2010 at: http://www.theamericanscholar.org/the-decline-of-the-english-department/

Damasio, A. (2003). Looking for Spinoza: Joy, sorrow, and the feeling brain. New York: Harcourt. Dewey, J. (1934/2005). Art as experience. New York: Penguin Books.

Fraleigh, W. (1984). Right actions in sport: Ethics for contestants. Champaign, IL: Human Kinetics. Gardner, H. (1983). Frames of mind: The theory of multiple intelligences. New York: Basic Books. Kelso, S. \& Engstrom, D. (2006). The complementary nature. Cambridge, MA: The MIT Press.

Leder, D. (1990). The absent body. Chicago: University of Chicago Press.

McGinn, C. (1999). The mysterious flame: Conscious minds in a material world. New York: Basic Books. Merleau-Ponty, M. (1942/1963). The structure of behavior. Translated by A. L. Fisher. Boston: Beacon Press. Sheets-Johnstone, M. (1999). The primacy of movement. Amsterdam/Philadelphia: John Benjamins Company. Suits, B. (1978/2005). The grasshopper: Games, life and utopia. Toronto: Broadview Encore Press.

Wild, J. (Ed.) (1930/1958). Spinoza selections. New York: Charles Scribner’s Sons.

AUTHOR'S ADDRESS: $\quad$ R. Scott Kretchmar Pennsylvania State University Department of Kinesiology 268K Recreation Building; University Park, PA 16802, USA

Email: rsk1@psu.edu 